\title{
Use of Laryngeal Mask Airways in Pediatric Tonsillectomies and Adenoidectomies Retrospective Outcome Study
}

\author{
Monika Feeney* \\ Missouri State University, School of Anesthesia, USA \\ Submission: March 14, 2019; Published: April 02, 2019 \\ *Corresponding author: Monika Feeney, Missouri State University, School of Anesthesia, USA
}

\begin{abstract}
Pediatric tonsillectomies and adenoidectomies (T \& A's) have historically been done using endotracheal tubes with general anesthesia. This study is a retrospective comparison study of a large number of pediatric cases done in one institution using laryngomask Airways (LMA's) in the pediatric surgical population. Coblation was used for hemostasis. Data collected showed a statistically significant decrease in post op complications when compared to T \& A's done with endotracheal tubes.
\end{abstract}

Keywords: T \& A; Pediatric tonsillectomy; LMA use

\section{Introduction}

Nationally 400,000 Tonsillectomy and Adenoidectomy procedures (T \& A) are performed yearly. Barash (2006) tells us T $\& \mathrm{~A}$ is one of the more common pediatric procedures performed. Indications for performing a $\mathrm{T} \& \mathrm{~A}$ include chronic or recurrent acute tonsillitis, peritonsillar abscess, tonsillar hyperplasia, and obstructive sleep apnea syndrome. Pediatric patients are placed under general anesthesia, and an Endotracheal Tube (ET) introduced in the airway to allow ventilation during the procedure.

ET tubes have been used successfully for decades. Anesthesia providers are skilled at placement; however according to Webster [1] complications include trauma, cardiovascular stimulation, endobronchial intubation, bronchospasm, laryngospasm, edema and obstruction after extubation can all occur with ET tube use. An alternative airway device, the Laryngeal Mask Airway (LMA), is a relatively recent tool developed by Dr. Archie Brain in the 1980 's. It is a supraglottic device that allows ventilation control at a modest level. It is easy to insert, minimal stimulation is associated with its use, it gives partial protection of secretions, and hands-free ventilation. Clinical guidelines show limits to its use on patients with esophageal reflux, morbidly obese, hiatal hernia's or pulmonary compliance that is reduced [2]. Patient positioning is another factor that can limit the use of the LMA.

Limited studies exist reflecting the safety of LMA's in T\&A's. Moller, in Evidence Based Anesthesia reports 2 surveys done the first in 1996 in France where only 2\% of T \& A cases used LMA's, and then again in 1999 in England, 16\% of T \& A cases were done with LMA's. A 9.5\% conversion rate was found in 3 other studies and usually occurred at the time of insertion. Conversion meaning an LMA was attempted, then for whatever reason switched to an ET tube. European countries use LMA's seemingly much more commonly than in the US, studies have even been done using them on prone cases. In 1994, Splinter et al. published a study with an $\mathrm{n}$ of 112 , judging pain post operatively, and found no difference found in pain scores between the use of an LMA or ET tube. 1993 William Bailey used a reinforced LMA and compared it to ET tube use in ASA 1 or 2 patients, and concluded that perhaps it was a good substitute, $(n=104)$ of 104 pediatric patients.

In 1995 Ruby et al. published a study with 109 pediatric participants using LMA's and concluded a decreased aspiration, decreased bleeding, and decreased laryngospasm. The study was not standardized to what type of surgery and did describe difficulty placing the LMA if enough anesthetic depth was not achieved. Hern et al. [3] in 1999 compared surgical access in a study with 90 patients, $44 \mathrm{LMA}$, and $47 \mathrm{ET}$ tube, his conclusions were LMA's are inferior for surgical access. The largest study to date is Daum \& O Reilly [4] in 1992 an 18-month study of the usefulness of the LMA in ENT surgery, 217 patients showing no complications if adequate depth of anesthesia was obtained prior to insertion. Cardiovascular effects were decreased, and they concluded an LMA 
was acceptable adjunct when the airway is shared in Ear, Nose and Throat (ENT) surgery. Is instrumenting the airway necessary to perform a safe anesthetic? Is using one airway adjunct any different than another common one, and are there any differences in complications?

\section{Methods}

Historically T \& A's are almost 100\% done using tracheal intubation. A retrospective chart review was completed in a major Level One Trauma Center. No patient identifiers were used data collection was collected electronically with specific criteria. For the purposes of this retrospective investigation, initially there were 2 variables investigated. Choice 1: All went well with the case, Choice 2 something went wrong or there was a complication of the procedure due to the airway device. Choice 2, the complication category was then divided into 6 categories,
a) 0 being none,
b) 1: meaning suction required,
c) 2: a cough occurred,
d) 3: a decrease in $\mathrm{SPO}$,
e) $4:$ stridor,

f) 5: multiple respiratory complications, and

g) 6: laryngospasm.

Selection criteria included children ages 3 to 12 , and all studied were having elective outpatient T\&A surgery. It was decided that post-operative bleeding was a surgical complication, not an airway device complication [5]. A coblator was used $100 \%$ of the time on all T\&A procedures. Coblation technology combines radiofrequency energy with saline to remove tissue and causes minimal damage to surrounding areas. Greater than 500 cases were reviewed and during this period no post-operative bleeding occurred.

Inclusion criteria for this study was ASA 1 or 2 pediatric patients ages 3 to 12 and having no other surgical procedures. All inductions were inhalational or IV without the use of muscle relaxants. Re-admissions for re-explorations, conversion from LMA to ETT, nausea and respiratory complications were tracked, as well as operating room time. All children got an average of $1.2 \mathrm{mcg} / \mathrm{kg}$ fentanyl during the inter-operative period.

\section{Results}

537 charts were reviewed, 306 LMA's used, and 231 ET tubes. The frequency of doing the procedure with an ET tube or an LMA is shown in the following chart (Figure 1).

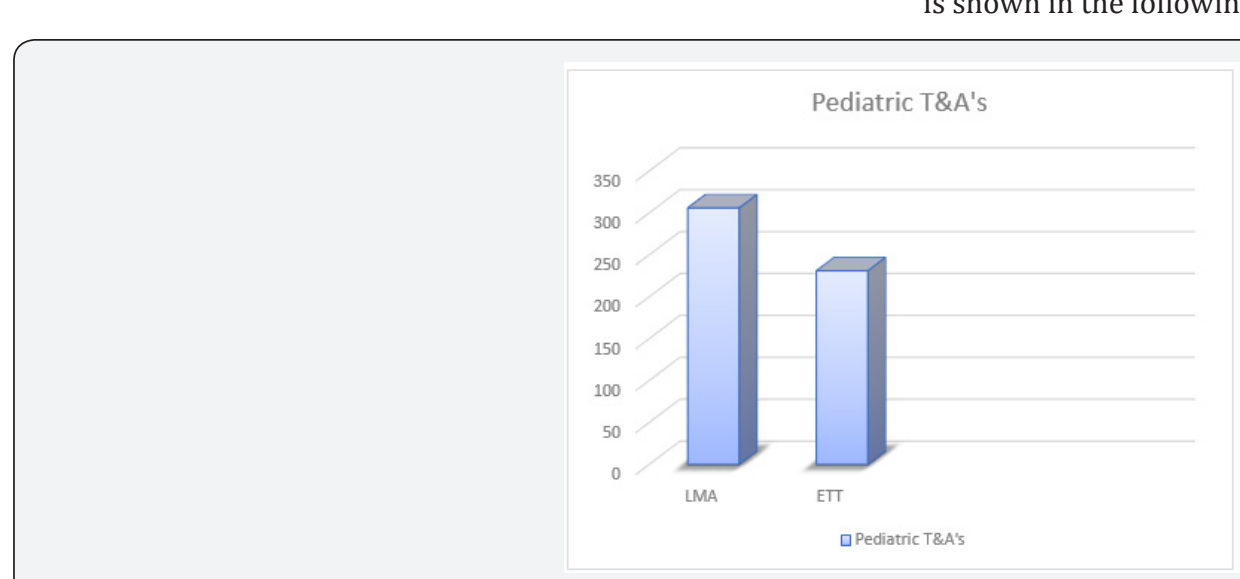

Figure 1: Pediatric T \& A's Airway Device Used.

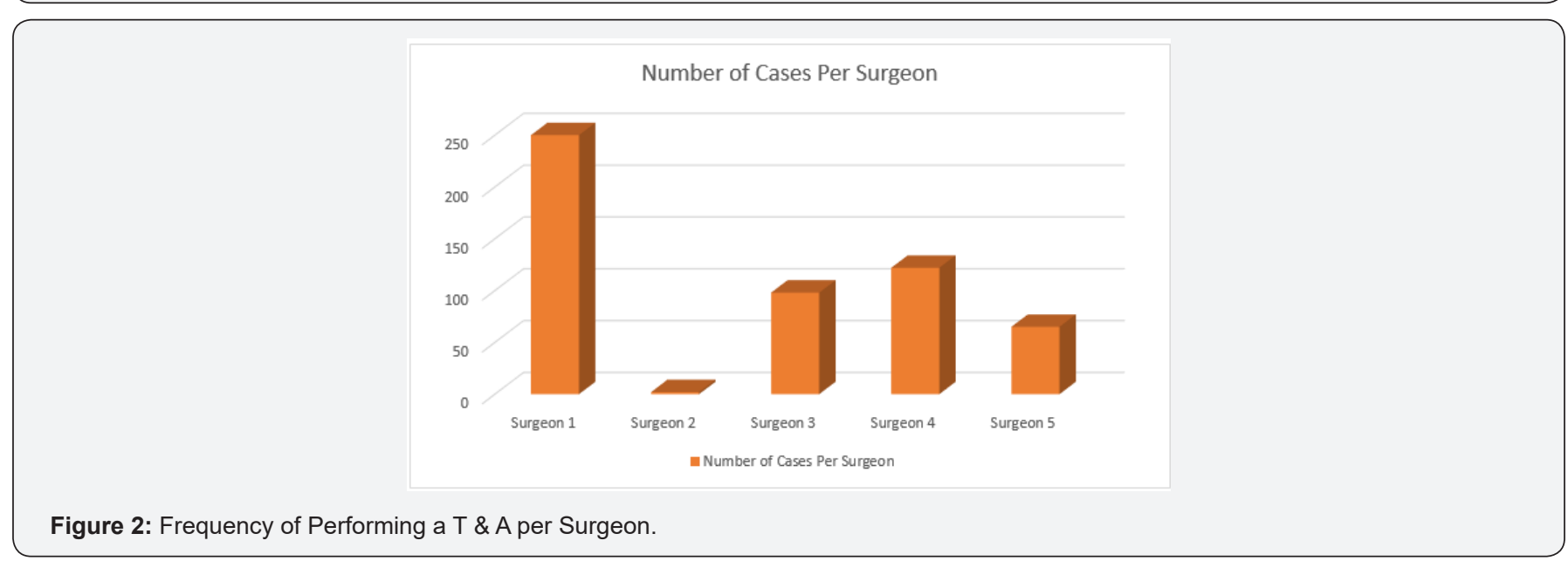




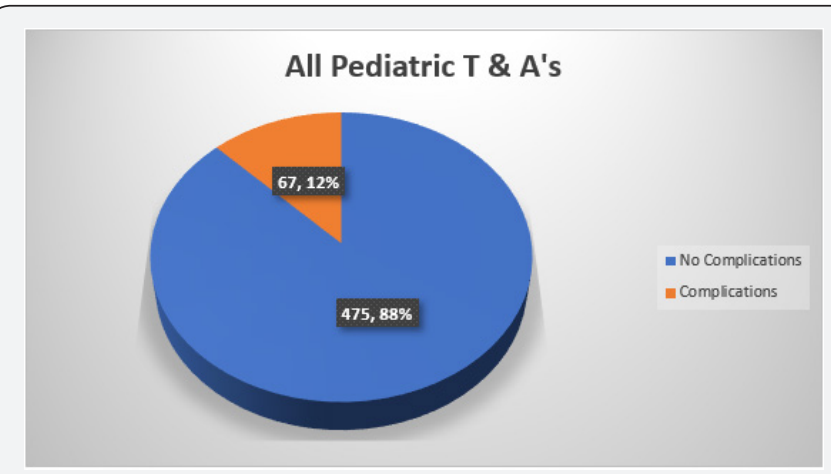

Figure 3: Total cases, Complications and no Complications.

Five Surgeons were included in the study performing the surgical T \& A are shown with their frequency of their performance of this operation. Numbers 1 through 5 correlates with a specific surgeon. Surgeon specific frequencies are noted in Figure 2. From the data, the following additional information was extracted: Complications were notes as yes (1), or no (2) for all patients (Figure 3).

If complications were noted, they were divided into categories:

a) 0 being none;

b) 1 meaning suction required;

c) 2 a cough occurred;

d) 3 a decrease in $\mathrm{SpO2}$

e) 4 Stridor;

f) 5 Multiple respiratory complications; and

g) 6 Laryngospasm.

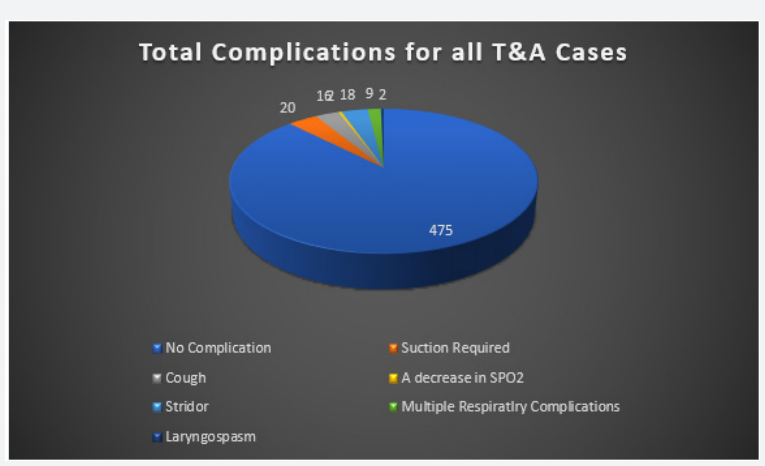

Figure 4: Total Complications for all T\&A Cases.

A single incident of any of the complications the case was counted. For example, one cough, any documented decrease in oxygen saturation [6]. Totals are shown in all of the T\&A cases (Figure 4). ET tubes were analyzed separately from the LMA cases. The seven categories were unchanged (Table 1). Analysis revealed 90 percent of cases there were no complications with LMA use, compared with 83 percent of the time a complication appears with the ET tube. The question becomes is 83 percent versus 90 percent significant, with the number of charts reviewed? Table 2 shows the data of Unexpected outcomes comparing LMA's vs ETT's.

Table 1: 5 ETT vs. LMA Complications.

\begin{tabular}{|c|c|c|c|}
\hline & ET Tube & LMA \\
\hline 0 & $\begin{array}{c}\text { No complica- } \\
\text { tions }\end{array}$ & 199 & 276 \\
\hline 1 & Suction & 7 & 13 \\
\hline 2 & Cough & 12 & 4 \\
\hline 3 & $\begin{array}{c}\text { Decrease in } \\
\text { SPO2 }\end{array}$ & 2 & 0 \\
\hline 4 & Stridor & 10 & 8 \\
\hline 5 & $\begin{array}{c}\text { Multiple Resp. } \\
\text { Complications }\end{array}$ & 5 & 4 \\
\hline 6 & Laryngospasm & 2 & 0 \\
\hline
\end{tabular}

Table 2: 5 Unexpected outcomes comparing LMA vs ETT.

\begin{tabular}{|c|c|c|}
\hline Complications & None & Unexpected Outcome \\
\hline LMA & 276 & 29 \\
\hline Endotracheal tube & 199 & 38 \\
\hline
\end{tabular}

A statistically significant difference between the 2 methods of airway management is noted. Chi square greater than 5 with a $p$ value of .022. The conclusion can be made that using an LMA in pediatric T \& A procedures is as safe as using ET tubes, but statistically significant less unexpected/ unwanted outcomes occur. Frequency of respiratory complications are greater with ET tubes.

\section{Discussion/Conclusion}

Significantly less unwanted outcomes occurred when an LMA was used compared to an ET tube for pediatric T \& A's in this retrospective chart review. It is noted that a skilled surgeon using a coblator is used consistently in all cases reviewed. A noted limitation is a retrospective chart review, multiple anesthesia providers with different charting techniques. Data collection was done by 2 students that consistently completed data collection sheet.

Further study will perhaps show this is not only safer by causing fewer complications, less OR time is required and therefore more cost effective. Currently the results of the time data show an overall 4 minute shorter OR time for T \& A's using LMA's than those using ET tubes. When estimated at 500 cases a year, a cost savings could be realized.

Data collection thanks to the following CRNA students: M Fann, M Schuster and D. Pennington.

\section{References}

1. Webster A, Morley Forster PK, Dain S, Ganapathy S, Ruby R, et al. (1993) Anaesthesia for adenotonsillectomy; a comparison between tracheal intubation and the armoured laryngeal mask airway. Canadian Journal of Anaesthesia 40(12): 1171-1177.

2. Brimacombe J, Berry A (1995) IPPV and the laryngeal mask airway what are the risks? Today's Anesthetist 10: 5. 
3. Hern J, Jayaraj SM, Sidhu VS, Almeyda JS, O Neill G, et al. (1994) The laryngeal mask airway in tonsillectomy: the surgeon's perspective. Clinical Otolaryngology 24(2):122-125

4. Daum, RE (1992) The laryngeal mask in ENT surgery. Journal of Laryngology and Otology 106(1): 28-30.

This work is licensed under Creative Commons Attribution 4.0 License

DOI: 10.19080/JAICM.2019.08.555744
5. Barash PG, Bruce F Cullen, Robert K Stoelting, Michael K Cahalan, John W. Bethea, et al. (2009) Clinical Anesthesia. ( $6^{\text {th }}$ Edn), PA: Lippincott Williams \& Wilkins, Philadelphia 112: 767-768.

6. Moller A (2006) Evidence-based Anaesthesia and Intensive Care. Cambridge Press, Herlev University, Denmark, pp. 272.

\section{Your next submission with Juniper Publishers will reach you the below assets}

- Quality Editorial service

- Swift Peer Review

- Reprints availability

- E-prints Service

- Manuscript Podcast for convenient understanding

- Global attainment for your research

- Manuscript accessibility in different formats ( Pdf, E-pub, Full Text, Audio)

- Unceasing customer service

Track the below URL for one-step submission https://juniperpublishers.com/online-submission.php 